Fixed Point Theory, 21(2020), No. 2, 727-738

DOI: $10.24193 /$ fpt-ro.2020.2.52

http://www.math.ubbcluj.ro/ nodeacj/sfptcj.html

\title{
ALGORITHMS FOR APPROXIMATING SOLUTIONS OF EQUILIBRIUM PROBLEMS AND FIXED POINTS OF NONEXPANSIVE-TYPE SEMIGROUP
}

\author{
O.M. ROMANUS*, U.V. NNYABA** AND M.O. NNAKWE*** \\ *African University of Science and Technology, Abuja, Nigeria \\ E-mail: rromanus@aust.edu.ng \\ **African University of Science and Technology, Abuja, Nigeria \\ E-mail: nukamaka@aust.edu.ng \\ ***African University of Science and Technology, Abuja, Nigeria \\ E-mail: mondaynnakwe@gmail.com
}

\begin{abstract}
In this paper, a Krasnoselskii-type and a Halpern-type algorithms for approximating a fixed point of a totally quasi- $\phi$-asymptotically nonexpansive multi-valued semigroup and a solution of a generalized mixed equilibrium problem is studied. Strong convergence of the sequences generated by these algorithms is proved in real Banach spaces. Finally, the theorems proved are significant improvement on several important recent results.

Key Words and Phrases: Halpern-type algorithm, Krasnoselskii-type algorithm, generalized mixed equilibrium problems, totally quasi- $\phi$-asymptotically nonexpansive multi-valued maps, equally continuous maps.
\end{abstract}

2010 Mathematics Subject Classification: 47H10, 47H04, 47J25, 47J20.

\section{REFERENCES}

[1] Ya. Alber, Metric and generalized projection operators in Banach spaces: properties and applications. In: Theory and Applications of Nonlinear Operators of Accretive and Monotone Type (Ed. A.G. Kartsatos), Marcel Dekker, New York, 1996, 15-50.

[2] A. Barbagallo, Existence and regularity of solutions to nonlinear degenerate evolutionary variational inequalities with applications to dynamic network equilibrium problems, Applied Mathematics and Computation, 208(2009), 1-13.

[3] E. Blum, W. Oettli, From optimization and variational inequalities to equilibrium problems, The Mathematics Student, 63(1994), no. 1-4, 123-145.

[4] N. Buong, Hybrid Ishikawa iterative methods for a nonexpansive semigroup in Hilbert space, Computational Mathematics and Application, 61(2011), 2546-2554.

[5] L.C. Ceng, J.C. Yao, A hybrid iterative scheme for mixed equilibriun problems and fixed point problem, Journal of Computational and Applied Mathematics, 214(2008), 186-201.

[6] S.S. Chang, H.W.J. Lee, C.K. Chan, Convergence theorem of common fixed point for asymptotically nonexpansive semigroups in Banach spaces, Applied Mathematics and Computation, 212(2009), 60-65.

[7] S.S. Chang, L. Yang, J.A. Liu, Strong convergence theorem for nonexpansive semi-groups in Banach spaces, Applied Mathematics and Mechanics, 28(2007), 1287-1297. 
[8] I. Cioranescu, Geometry of Banach Spaces, Duality Mappings and Nonlinear Problems, Kluwer Academic Publishers, Dordrecht, The Netherlands, 1990.

[9] S. Dafermos, A. Nagurney, A network formulation of market equilibrium problems and variational inequalities, Operation Research Letters, 3(1984), 247-250.

[10] K. Fan, A Minimax Inequality and Applications, Inequality III (O. Shisha, ed.), Academic Press, New York, 1972, 103-113.

[11] Q. Feng, Y. Su, F. Yan, Modified hybrid block iterative algorithm for uniformly quasi- $\phi-$ nonexpansive mappings, Abstract and Applied Analysis, (2012), DOI: 10.1155/2012/215261.

[12] Y. Haugazeau, Sur les Inequations Variationnelles et la Minimization de Fonctionnelles Convexes, Doctoral Thesis, University of Paris, France, 1968.

[13] S. Kamimura, W. Takahashi, Strong convergence of a proximal-type algorithm in a Banach space, SIAM J. Optimization, 13(2002), no. 3, 938-945.

[14] A. Moudafi, M. Thera, Proximal and Dynamical Approaches to Equilibrium Problems, Lecture Notes in Economics and Mathematics systems, vol. 477, Springer, 1999, 187-201.

[15] G. Stampacchia, Formes bilineaires coercitives sur les ensembles convexes, C. R. Acad. Sci. Paris, 258(1964), 4413-4416.

[16] T.V. Su, Second-order optimality conditions for vector equilibrium problems, J. Nonlinear Functional Analysis, 2015(2015), 31 pages.

[17] T. Suzuki, On strong convergence to common fixed points of nonexpansive semigroups in Hilbert spaces, Proc. Amer. Math. Soc., 131(2003), 2133-2136.

[18] D.V. Thong, An implicit iteration process for nonexpansive semigroups, Nonlinear Anal., (2011), DOI: $10.1016 /$ j.na 2011.05.090.

[19] H.K. Xu, A strong convergence theorem for contraction semigroups in Banach spaces, Bull. Australian Mathematical Society, 72(2005), 371-379.

[20] Y. Yao, Y.J. Cho, Y.C. Liou, Hierarchical convergence of an implicit double-net algorithm for nonexpansive semigroups and variational inequalities, Fixed Point Theory and Applications, 101 (2011), DOI: 10.1186/1687-1812-2011-101.

[21] S.S. Zhang, Generalized mixed equilibrium problem in Banach spaces, Applied Mathematics and Mechanics, 30(2009), no. 9, 1105-1112.

[22] S. Zhang, L. Wang, Y. Zhao, Multi-valued totally quasi- $\phi$-asymptotically nonexpansive semi-groups and strong convergence theorems in Banach spaces, Acta Mathematica Scientia, 33B(2013), no. 2, 589-599.

Received: June 18, 2018; Accepted: January 10, 2019. 